\title{
Development of Geographic Fatty Liver
}

\author{
Satoshi Nakayama and Naoya Murashima
}

Key words: geographic fatty liver, alcoholic hepatitis, arterioportal maldistribution

(Intern Med 52: 1421-1422, 2013)

(DOI: 10.2169/internalmedicine.52.0418)

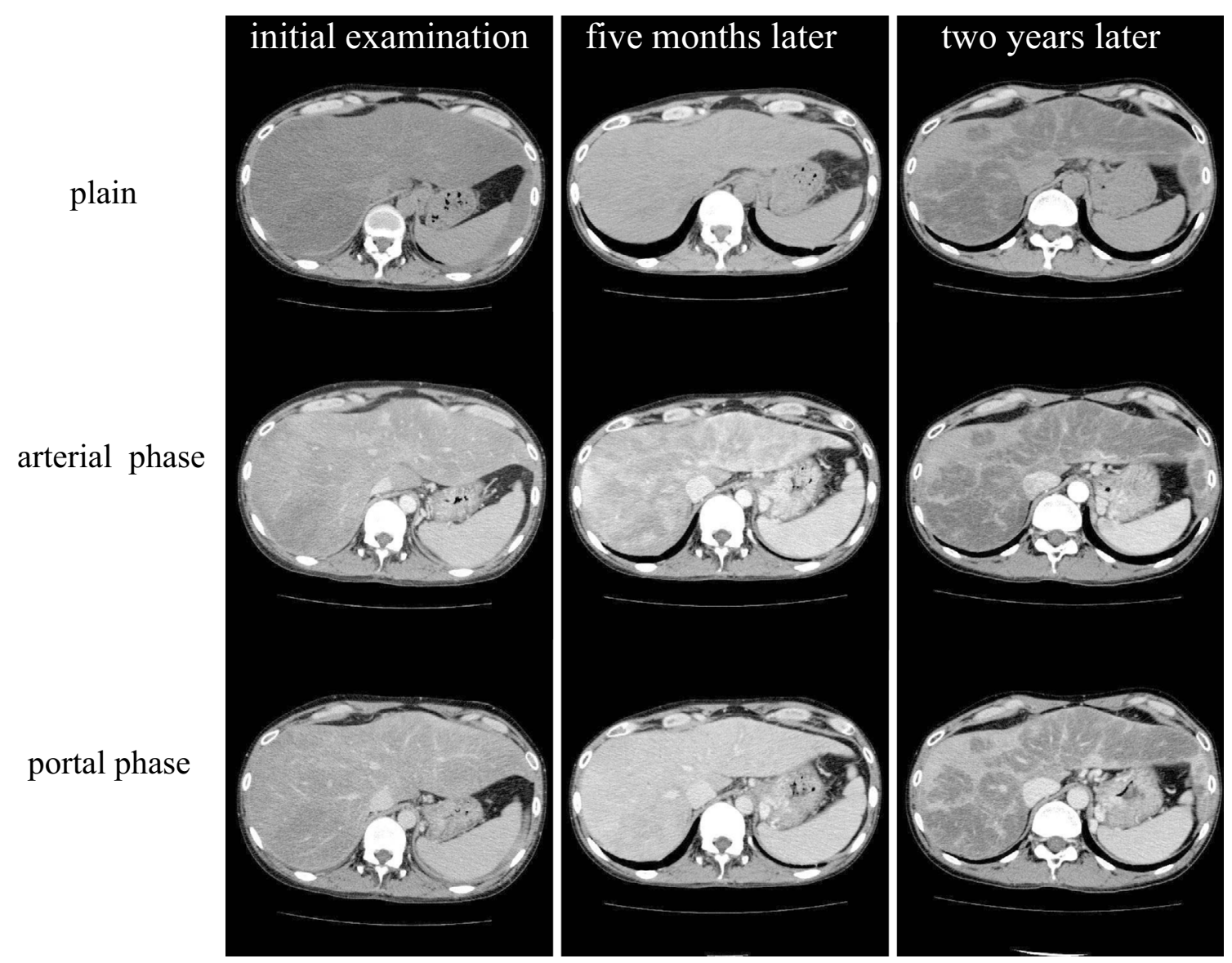

Picture.

Geographic fatty liver is sometimes revealed on computed tomography (CT) images. In patients with this condition, perivascular fat deposition characterized by halos of fat surrounding the hepatic and/or portal vein develops; however, the pathogenesis remains unknown $(1,2)$.

A 30-year-old man developed severe alcoholic hepatitis. Initial abdominal CT revealed homogeneous fatty liver with mild maldistribution of the arterioportal blood flow. After five months of abstinence, CT showed a resolution of the steatosis in addition to the development of more obvious arterioportal maldistribution, possibly associated with liver regeneration. Dominant areas of arterial flow were enhanced geographically in the arterial phase and became obscure in the portal phase. Two years after the initial examination, the patient began drinking again, and CT disclosed geographic periportal fat deposition throughout the entire liver. The areas without fat deposition corresponded approximately to arterial dominant areas. 
Accordingly, a territorial reduction of the portal blood flow may have contributed to the formation of geographic fatty liver in this patient.

The authors state that they have no Conflict of Interest (COI).

\section{References}

1. Hamer OW, Aguirre DA, Casola G, et al. Imaging features of perivascular fatty infiltration of the liver: initial observations. Radiology 237: 159-169, 2005.

2. Hamer OW, Aguirre DA, Casola G, et al. Fatty liver: imaging patterns and pitfalls. Radiographics 26: 1637-1653, 2006.

(C) 2013 The Japanese Society of Internal Medicine

http://www.naika.or.jp/imonline/index.html 